\title{
Comparison of oral treatment of uncomplicated urogenital and rectal gonorrhoea with cefuroxime axetil ester or clavulanic acid potentiated amoxycillin (Augmentin)
}

\author{
R SCHIFT,* J van ULSEN,* M C ANSINK-SCHIPPER, $†$ Th van JOOST,* M F MICHEL, $¥ \mathrm{R} \mathrm{K}$ \\ WOUDSTRA, $\dagger$ AND E STOLZ*
}

From the ${ }^{*}$ Department of Dermatovenereology, University Hospital, Rotterdam, the $\dagger$ Laboratory for Public Health, Amsterdam, and the $\ddagger$ Department of Clinical Microbiology and Antimicrobial Therapy, Erasmus University, Rotterdam, the Netherlands

SUMMARY In a randomised study of two drugs for the oral treatment of uncomplicated urogenital and rectal gonorrhoea the therapeutic effect of cefuroxime axetil ester (CAE) and amoxycillin plus clavulanic acid $(\mathrm{A}+\mathrm{C})$ was compared. Cefuroxime axetil ester $1.5 \mathrm{~g}$ was given to 129 men and 118 women. Amoxycillin $3.0 \mathrm{~g}$ and clavulanic acid $0.25 \mathrm{~g}$ was given to 131 men and 122 women. Both treatments were combined with probenecid $1.0 \mathrm{~g}$ and administered in a single oral dose. Of the 500 patients thus treated, 376 were assessable. In the group taking CAE, failure rates were $0.9 \%$ for the men and $0 \%$ for the women; and the overall failure rate was $0.5 \%$. In the group taking $A+C$ the equivalent failure rates were $4.6 \%, 1.2 \%$, and $3.1 \%$. The differences were not significant. Penicillinase producing Neisseria gonorrhoeae (PPNG) was isolated from 5.6\% of the assessable patients. All 10 PPNG infections in the group taking CAE and four of 11 PPNG infections in the group taking $\mathrm{A}+\mathrm{C}$ were cured. These numbers were too small to draw a definite conclusion about the efficacy of both drugs in this type of infection. Postgonococcal urethritis was observed in $35 \%$ of the men in the group taking $\mathrm{CAE}$ and in $32 \%$ of those in the group taking $\mathrm{A}+\mathrm{C}$. Side effects were noted in $38 \%$ of the group taking $\mathrm{CAE}$ and $28 \%$ of the group taking $\mathrm{A}+\mathrm{C}$. Nausea and vomiting were more commonly observed in the group taking $\mathrm{CAE}$; and diarrhoea was more commonly observed in the group taking $\mathrm{A}+\mathrm{C}$.

\section{Introduction}

During the past few years cefuroxime, administered intramuscularly in a dose of $1.5 \mathrm{~g}$, has been the drug of choice for treating uncomplicated urogenital and rectal gonorrhoea, caused by either penicillinase (PPNG) or non-penicillinase (non-PPNG) producing strains of Neisseria gonorrhoeae in our hospital. ${ }^{2}$ Since the introduction of this treatment few treatment failures have been observed in these types of infection. ${ }^{3}$ The rate of cure for oropharyngeal gonorrhoea, however, was disappointing. ${ }^{2}$

A disadvantage of cefuroxime is its parenteral form

Address for reprints: Dr R Schift, Department of Dermatovenereology, University Hospital, 40 Dr Molewaterplein, 3015 GD Rotterdam, the Netherlands

Accepted for publication 20 December 1985 of administration. Cefuroxime has also recently become available as cefuroxime axetil ester (CAE) for oral administration. CAE is a pro-drug of cefuroxime: after absorption, mainly from the stomach, cefuroxime only can be shown in serum and urine. The highest concentration in the serum is observed two to two and a half hours after the dose. ${ }^{4}$

Clavulanic acid suppresses the activity of $\beta$ lactamases that are produced by various microorganisms, such as Staphylococcus aureus, Haemophilus spp, and $\mathbf{N g o n o r r h o e a e . ~}{ }^{5}$ Augmentin, a combination of amoxycillin and clavulanic acid in a ratio of 4:1, is active against these $\beta$ lactamase producing micro-organisms. De Koning et al observed a failure rate of $7.5 \%$ in 51 patients with urogenital gonorrhoea caused by PPNG and treated with amoxycillin $3.0 \mathrm{~g}$, clavulanic acid $0.5 \mathrm{~g}$ (a ratio of 6:1), and probenecid $1.0 \mathrm{~g}$. 
As both CAE and Augmentin can be given orally in combination with probenecid, and both agents are active in vitro against PPNG as well as non-PPNG, we decided to compare the therapeutic effect of the agents in a single blind randomised study in men and women with uncomplicated urogenital and rectal gonorrhoea.

\section{Patients, materials, and methods}

Consecutive men and women attending the venereological outpatient department of the University Hospital, Rotterdam, who had urogenital and rectal gonorrhoea, or who were sexual contacts of men with confirmed urethral gonorrhoea, were studied. The trial was designed to treat a sufficient number of patients with doses of CAE or A+C to obtain an assessable quota $(200,100$ men and 100 women in each group). Randomisation, stratified by sex, was performd by using sealed envelopes. Patients were either treated with CAE $1.5 \mathrm{~g}$ (three tablets of 0.5 $\mathrm{g}$ ), together with probenecid $1.0 \mathrm{~g}$ (two tablets of $0.5 \mathrm{~g}$ ) in a single oral dose, or with a combination of amoxycillin $3.0 \mathrm{~g}$ and clavulanic acid $0.25 \mathrm{~g}$ (ratio $12: 1$ ), together with probenecid $1.0 \mathrm{~g}$ (two tablets of $0.5 \mathrm{~g}$ ) in a single oral dose. Amoxycillin and clavulanic acid were given as a dose of two tablets of Augmentin $(0.625 \mathrm{mg}$ each) and four disperse tablets of amoxycillin $(0.5 \mathrm{~g}$ each).

Patients were excluded from the study for the following reasons: hypersensitivity to penicillin or cephalosporins; recent or simultaneous treatment with other antibiotics; pregnancy or lactation. If the patient vomited within two hours after treatment the results were not analysed. Patients with oropharyngeal gonorrhoea were also excluded from the study.

\section{DIAGNOSIS}

The procedures used to detect gonococcal infection have been described previously. ${ }^{13}$ If Gram negative diplococci were found in a Gram stained smear, treatment was started before results of the culture were known, with one of the two agents. Female sexual contacts of men with confirmed urethral gonorrhoea were also studied if the result of the Gram stained smear was negative. Only patients with a positive culture were considered to be assessable. Of all strains isolated before and after treatment, sensitivity to cefuroxime, amoxycillin, amoxycillin plus $2 \mathrm{mg} / 1$ clavulanic acid, amoxycillin plus $5 \mathrm{mg} / 1$ clavulanic acid, penicillin $\mathrm{G}$, and tetracycline were determined by the agar diffusion method. Sensitivities were expressed as minimum inhibitory concentration (MIC) in $\mathrm{mg} / \mathrm{l}$. Using twofold dilutions, these antibiotics were tested over the following ranges: 0.005 to $0.64 \mathrm{mg} / 1$ for cefuroxime and 0.005 to $0.124 \mathrm{mg} / 1$ for the other antibiotics. ${ }^{7}$ If gonorrhoea persisted after treatment an auxanographic typing, as described previously, ${ }^{8}$ was also undertaken. If gonococci were found in more than one location we used the urethral and cervical isolates in men and women, respectively, for determining the MIC and auxotype. All isolates were screened for $\beta$ lactamase production by the chromogenic cephalosporin test (Nitrocephin, Glaxo). At the second visit a two glass urine test was performed on the men. If more than 10 leucocytes per microscopic field (x250) were found in the sediment of the first voided $10-15 \mathrm{ml}$ of urine the patient was considered to have postgonococcal urethritis.

\section{FOLLOW UP}

Patients were asked to return one week after treatment when all procedures were repeated. Information was gathered about the possible side effects of the drugs by explicitly questioning the patients. If gonorrhoea persisted after treatment a new treatment with the concurrent drug was given (cross over treatment). If gonorrhoea still persisted after the second drug had been given patients received an intramuscular injection of cefuroxime $1.5 \mathrm{~g}$.

\section{ASSESSABLE PATIENTS}

Only those patients with a positive culture were assessable, whatever the result of the Gram smear microscopy. Patients who had persistent gonorrhoea but who had had sexual intercourse after treatment were considered to have been reinfected and were therefore not assessed. If gonococcal infection persisted in patients after treatment and the patient had not had intercourse in the intervening period, but there were considerable differences in MIC and auxotype of the strains isolated at the first and second visits, these patients were also considered to be reinfected and were therefore excluded from the study.

This study was approved by our hospital ethical committee.

\section{Results}

In all, 260 men and 240 women were treated. Of the men, 129 were treated with $C A E$ and 131 with $A+C$. Of the women, 118 were treated with $\mathrm{CAE}$ and 122 with $\mathrm{C}+\mathrm{A}$. The age distribution in each group was similar. The average age of the men was 31 years (range 16-61) in the group taking CAE and 30 years (range 16-59) in the group taking $\mathrm{C}+\mathrm{A}$. For the women this was 26 years (range 14-47) in the group taking CAE and 28 years (range 17-47) in the group taking $\mathrm{A}+\mathrm{C}$. Of the men, $65 \%$ treated with $\mathrm{CAE}$ and $74 \%$ of those treated with $A+C$ were white, whereas $26 \%$ and $19 \%$, respectively, were black. Of the women, $84 \%$ and $75 \%$, respectively, were white, and $7 \%$ and $17 \%$, respectively, were black. Of the 500 
patients treated, 376 were assessable: 185 of 247 patients ( 107 men and 78 women) and 191 of 253 (108 men and 83 women) in the group taking CAE and $A+C$, respectively. Patients in the group taking CAE were not assessed for the following reasons: negative cultures ( 29 patients, 6 men and 23 women); patient default (23 patients, 11 men and 12 women); concurrent treatment (one woman); vomiting (one man and one woman); and reinfections (seven patients, four men and three women). All the women with reinfection had had intercourse after treatment, as had two of four men. The remaining two men were assumed to be reinfected because the strains isolated at the first and second visit were not identical. Patients in the group taking $\mathrm{A}+\mathrm{C}$ were not assessed for the following reasons: negative cultures (27 patients, six men and 21 women); patient default (16 patients, 10 men and six women); vomiting (one woman); oropharyngeal gonorrhoea (one man and one woman); and reinfections ( 16 patients, six men and 10 women). In five of six men a reinfection was assumed on the basis of the history (intercourse after treatment) and in one man based on the MIC and auxotype differences of strains. All 10 women with reinfection had had intercourse after treatment.

Positive cultures from the urethra were found in $95.5 \%$ of the men taking CAE and in $94.7 \%$ in the group taking $\mathrm{A}+\mathrm{C}$. A positive culture of the rectum only was found in $4.5 \%$ of the men in the group taking $\mathrm{CAE}$ and in $1.7 \%$ of the group taking A+C. In $96.3 \%$ of the women in the group taking $\mathrm{CAE}$ and in $91.4 \%$ in the group taking $\mathrm{A}+\mathrm{C}$ a positive culture of the cervix was found; for the urethra these figures were $81.5 \%$ and $74.2 \%$ respectively. A positive culture of the rectum only was found in $2.2 \%$ of the women in the group taking $\mathrm{A}+\mathrm{C}$. Table I shows the numbers and percentages of PPNG infections. The PPNG infections were found equally in both treatment groups.

TABLE I Numbers (\%) of penicillinase producing Neisseria gonorrhoeae (PPNG) isolated in assessable patients treated with $C A E$ or $A+C$

No of patients with PPNG/total no of patients

\begin{tabular}{llrl}
\cline { 2 - 4 } Antibiotic & \multicolumn{1}{c}{$C A E$} & \multicolumn{1}{c}{$A+C$} & Total \\
\hline Men & $4 / 107(3 \cdot 7)$ & $6 / 108(5 \cdot 6)$ & $10 / 215(4 \cdot 7)$ \\
Women & $6 / 78(7 \cdot 7)$ & $5 / 83(6 \cdot 0)$ & $11 / 161(6 \cdot 8)$ \\
Total & $10 / 185(5 \cdot 4)$ & $11 / 191(5 \cdot 8)$ & $21 / 376(5 \cdot 6)$ \\
\hline
\end{tabular}

CAE = cefuroxime axetil ester,

$\mathrm{A}+\mathrm{C}=$ amoxycillin and clavulanic acid.

FAILURE RATES

Table II shows the failure rates in assessable patients. Persistent gonorrhoea was observed in $0.9 \%$ of the men, $0 \%$ of the women, and in $0.5 \%$ of all the patients
TABLE II Numbers (\%) of persistent gonorrhoea (failure rates) in patients carrying identical strains* who had not had intercourse after treatment

\begin{tabular}{lllll}
\hline & \multicolumn{4}{l}{ No of failures/total no of patients (\%) } \\
\cline { 2 - 5 } Antibiotic & CAE & $A+C$ & $\begin{array}{l}\text { Fisher's } \\
\text { exact test }\end{array}$ & $\begin{array}{l}\text { Significance } \\
\alpha=0.5\end{array}$ \\
\hline Men & $1 / 107(0.9)$ & $5 / 108(4.6)$ & $\mathrm{p}=0.21$ & $\mathrm{NS}$ \\
Women & $0 / 78$ & $1 / 83(1 \cdot 2)$ & $\mathrm{p}=1.00$ & $\mathrm{NS}$ \\
Total & $1 / 185(0.5)$ & $6 / 191(3.1)$ & $\mathrm{p}=0.12$ & $\mathrm{NS}$ \\
\hline
\end{tabular}

* Identity was established by comparing MIC's and auxotypes of strains isolated at first and second visit.

in the group taking CAE. In the group taking $\mathrm{A}+\mathrm{C}$ these figures were $4.6 \%, 1 \cdot 2 \%$, and $3 \cdot 1 \%$, repespectively. These differences were not significant. The only man in the group taking CAE with persistent gonorrhoea had not had intercourse after treatment. At the second visit he had a positive urethral culture; but his strain did not grow at subculture. Though the MIC and auxotype for both strains could not be compared, this case was considered to be a treatment failure. The MIC of cefuroxime for the first isolation was $0.02 \mathrm{mg} / \mathrm{l}$ in this patient.

All 10 patients (four men and six women) in the group taking CAE with a PPNG infection were cured after the first treatment. In the group taking $A+C$ four (three men and one woman) of 11 patients with a PPNG infection had persistent gonorrhoea, which had also been caused by a PPNG strain. If the failure rates of the men, women, and the total number of patients in both groups are compared separately (table II) none of the differences in this type of infection was significant (Fisher's exact test: $p \geqq 0.09 ; \alpha=0.05$ ).

\section{CROSSOVER TREATMENT}

In the group taking CAE seven of eight patients with persistent gonorrhoea received further treatment with $A+C$. One woman received no further treatment with $A+C$, as there was a possibility of reinfection by a partner who already had been treated with $\mathrm{A}+\mathrm{C}$ and was not cured. In four of these seven patients the gonococcal infection was cured by $\mathrm{A}+\mathrm{C}$. Two of the remaining three patients did not return for review. One man still had urethral gonorrhoea on the third visit. This patient had had intercourse after the second treatment. In the group taking $A+C, 20$ of 22 patients with persistent gonorrhoea were treated with CAE: all 20 patients were cured. One patient refused any further oral treatment. The other patient received a different treatment because of salpingitis.

POSTGONOCOCCAL URETHRITIS

Postgonococcal urethritis was found in $39(35 \%)$ of 111 men treated with CAE and in $36(32 \%)$ of 114 
treated with $\mathrm{A}+\mathrm{C}$. The difference was not significant (Fisher's exact test; $p=0.57 ; \alpha=0.05$ ).

\section{SIDE EFFECTS}

Side effects were related mainly to gastrointestinal disorders. In the group taking CAE $86(38 \%)$ of 224 patients who returned for a review mentioned side effects. In the group taking $\mathbf{A}+\mathbf{C}$ side effects were mentioned by 67 (28\%) of 237 patients. This difference was significant (Fisher's exact test; $p=$ $0.02 ; \alpha=0.05$ ). Table III shows the differentiation of

TABLE III Distribution of main side effects in patients treated with $C A E$ and $A+C$

\begin{tabular}{lllll}
\hline \multicolumn{5}{c}{ No (\%) of patients with complaints } \\
\cline { 2 - 5 } Antibiotic & $\begin{array}{l}C A E \\
n=224\end{array}$ & $\begin{array}{l}A+C \\
n=237\end{array}$ & $\begin{array}{l}\text { Fisher's } \\
\text { exact test }\end{array}$ & $\begin{array}{l}\text { Significance } \\
\alpha=0.05\end{array}$ \\
\hline Diarrhoea & $7(3.1)$ & $27(11.4)$ & $\mathrm{p}=0.0004$ & Significant \\
Nausea & $68(30 \cdot 4)$ & $26(11.0)$ & $\mathrm{p}=0.0002$ & Significant \\
Vomiting & $60(26 \cdot 8)$ & $24(10 \cdot 1)$ & $\mathrm{p}=0.0002$ & Significant \\
\hline
\end{tabular}

side effects in diarrhoea, nausea, and vomiting, and related percentages. Diarrhoea was mentioned more often in the group taking $A+C$, nausea and vomiting being mentioned more often in the group taking CAE. All differences were significant. Exanthema was mentioned by one patient in the group taking $\mathrm{CAE}$ and by three in the group taking $A+C$. Other side effects, such as pain in the muscles and joints and malaise, were only mentioned sporadically.

\section{Discussion}

In this study we found many unassessable patients, especially women, because female contacts of male patients with confirmed urethral gonorrhoea had been included in the study before the results of the cultures were known. A substantial number of these cultures, however, remained negative. The number of men and women who did not return for review was about equal.

On the whole, failure rates were lower in the group taking CAE than in the group taking $A+C$. The differences, however, were not significant. Crossover treatment with CAE also showed good results: all 20 patients were cured. Four of five patients who had crossover treatment with $\mathrm{A}+\mathrm{C}$ were cured. The results of the crossover treatments were not incorporated in the failure rates.

Because the percentage of PPNG infection was lower than expected in the period covered by this study, the number of patients with a PPNG infection was too small to draw definite conclusions about the efficacy of both treatments in this type of infection. It should be noted that de Koning et al ${ }^{6}$ treated 51 patients infected with PPNG strains with a combination of amoxycillin and clavulanic acid in a ratio of 6:1 and found a failure rate of $7 \cdot 5 \%$. We found higher failure rates in PPNG infections, using a lower dose of $250 \mathrm{mg}$ clavulanic acid in a limited number of patients, as did Lawrence ${ }^{9}$ using a dose of $250 \mathrm{mg}$ and $125 \mathrm{mg}$ clavulanic acid, also in a limited number of patients with PPNG infections. Therefore, further study is needed in a large number of patients with PPNG infections. The effects of a dose of clavulanic acid higher than $250 \mathrm{mg}$ would be of interest.

The percentages of patients with postgonoccal urethritis receiving both treatments were high. This implies that further treatment is indicated in a relatively large number of cases, with a drug active against the micro-organisms that cause non-specific urethritis.

Both treatments showed a high proportion of side effects. In treatment with CAE complaints of nausea and vomiting predominated and in treatment with $\mathrm{A}+\mathrm{C}$ diarrhoea was the major complaint. Other lower doses, especially for treatment with CAE, might reduce the number and nature of side effects.

In our opinion the results of the treatments with $\mathrm{CAE}$ and $\mathrm{A}+\mathrm{C}$ of uncomplicated urogenital and rectal gonorrhoea were satisfactory. The results of the oral treatment with CAE were even better than those obtained a few years ago with the intramuscular administration of cefuroxime $(1.5 \mathrm{~g})$. Apart from the previously mentioned drawbacks, oral treatments with $\mathrm{CAE}$ and $\mathrm{A}+\mathrm{C}$ are a welcome addition to the limited number of other drugs that are available for the oral treatment of urogenital and rectal gonorrhoea.

\section{References}

1. Nayyar KC, Michel MF, Stolz E. Antibiotic sensitivities of gonococci isolated in Rotterdam and results of treatment with cefuroxime. British Journal of Venereal Diseases 1980; 56:249-51.

2. Stolz E, Ong L, Joost Th van, Michel MF. Treatment of noncomplicated urogenital, rectal and oropharnygeal gonorrhoea with intramuscular cefotaxime, $1.0 \mathrm{~g}$ or cefuroxime $1.5 \mathrm{~g} . \mathrm{J}$ Antimicrob Chemother 1984;14 (suppl B):295-9.

3. Hoop D de, Nayyar KC, Klingeren B van, Stolz E, Michel MF. Infections with non-penicillinase producing Neisseria gonorrhoea treated with cefuroxime: treatment failures. Sex Transm Dis 1982;4:200-1.

4. Wise R, Bennett SA, Dent J. The pharmacokinetics of orally absorbed cefuroxime compared with amoxycillin/clavulanic acid. J Antimicrob Chemother 1984;13:603-10.

5. Klingeren $B$ van, Wijngaarden $L J$ van. Inhibition of $\beta$ lactamase in penicillinase producing gonococci by clavulanic acid. J Antimicrob Chemother 1981;8:79-80.

6. Koning GAJ de, Tio D, Coster JF, Coutinho RA, AnsinkSchipper MC. The combination of clavulanic acid and amoxycillin (Augmentin) in the treatment of patients infected with penicillinase producing gonococci. J Antimicrob Chemother 1981;8:81-2. 
7. Koning GAJ de, Stolz E, Michel MF. Neisseria gonorrhoea, sensitivity to amoxycillin, penicillin, cefuxorime, tetracycline and spectinomycin of isolated strains in 1976. Ned Tijdschr Geneeskd 1979;123:1199-202.

8. Ansink-Schipper MC, Huikeshoven MH, Woudstra RK, et al. Epidemiology of PPNG infections in Amsterdam. British
Journal of Venereal Diseases 1984;60:23-8.

9. Lawrence AG, Shanson DC. Single dose oral amoxycillin $3 \mathrm{~g}$ with either $125 \mathrm{mg}$ or $250 \mathrm{mg}$ clavulanic acid to treat uncomplicated anogenital gonorrhoea. Genitourin Med 1985; 61:168-71. 